Raicea V. ${ }^{1}$, Moraru L. ${ }^{1,2}$, Kovacs Judith ${ }^{2}$, Suciu H., ${ }^{1,2}$, Deac R ${ }^{\cdot 2}$

\title{
Difficulties in myocardial protection, tactics and surgical technique in the surgical treatment of a giant pseudoaneurysm of the ascending aorta
}

\section{- case report -}

${ }^{1}$ Chirurgie Cardiovasculară, IUBCvT, Tg. Mureş

${ }^{2}$ UMF Tg. Mureş

\begin{abstract}
We present the case of a 65 years old patient, initially hospitalized at Regional Pneumology Clinic with marked fatigue, severe pulmonary symptoms (suddenly developed severe resting dyspnea, orthopnea, irritating cough), loss of appetite, weight loss and dysphagia. Chest radiography raises the suspicion of giant ascending aortic aneurysm. Echocardiography confirms the presence of the aneurysm, but CT scan with contrast and angiography showed a giant pseudoaneurysm of ascending aorta with severe local compression of the right lung hilum and right main bronchus and in posterior on the esophagus. Coronary angiography also shows significant compression and deformation of the left main coronary artery. Echocardiography reveals marked dilated ascending aorta in the suprabulbar portion without aortic insufficiency. Replacement of the ascending aorta was performed in extracorporeal circulation with a impregnated Dacron prosthesis. Because of technically difficult approach, the ascending aorta ( being the right anterolateral wall of the pseudoaneurysm) was incanculated via right axillary artery, the aortic crossclamp was performed initially transluminal with Foley catheter and later with classical metallic instruments, and myocardial protection was achieved initially by retrograde administration of cardioplegic solution with monitoring of lactic acid, $\mathrm{pH}$ and base excess simultaneous from coronary sinus and the coronary ostia during administration of cardioplegic
\end{abstract}

\section{Liviu Moraru}

UMF Tg. Mureş, Str. Gh. Marinescu Nr. 38, Tg. Mureş, Romania Email: dr.liviu.moraru@gmail.com solution. The postoperative evolution was favorable, the weaning from extracorporeal circulation was succeeded without inotropics, with a 48 hours length of stay in ICU, and the patient was discharged after 8 days postoperatively.

Keywords: ascending aorta pseudoaneurysm, myocardial protection, retrograde cardioplegia, axillar cannulation

\section{Introduction}

Ascending aortic pseudoaneurysm are rare diseases (under 1\%) and this is undoubtedly due to the high mortality associated with rupture of the aorta [1]) and very dangerous due to the high risk of spontaneous rupture into the pericardium with cardiac tamponade and, beside these, there are the technical difficulties of the surgical procedure and the myocardial protection. Always the pseudoaneurysm results from complications of cardiac surgery, in which the ascending aorta is cannulated or incised [2]. The conditions required for the formation of a pseudoaneurysm include substantial injury to the arterial wall, local hemorrhage or bulging of the arterial wall and tamponade by the surrounding soft tissue $[3,4]$. The amount of time required to convert a 
pulsating hematoma into a false aneurysm is unknown, although Groves observed such a transformation as early as 23 days [5]. The natural history of the pseudoaneurysm is continuous expansion and eventually ruptures [6].

\section{Case report}

We are presenting the case of a patient of 65 years old, hospitalized initially in a Pneumology Hospital, with marked fatigue, severe respiratory symptoms (resting dyspnea with orthopnea suddenly installed, irritative coughing, loss of weight and dysphagia. Paraclinically: chest radiography raises the suspicion of giant ascending aortic aneurysm (Figure 1).

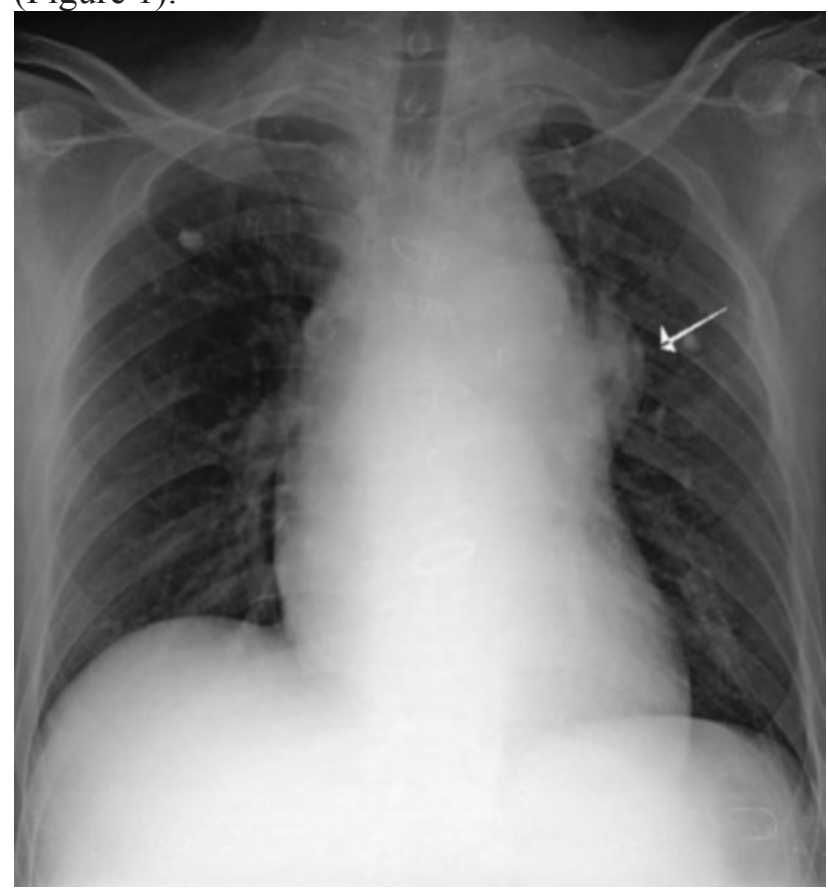

Figure 1

Echocardiography confirms dilated ascending aorta in the suprabulbar portion without aortic insufficiency, normal kinetics and good ejection fraction $(60 \%)$, normal valves and no pathologic pericardial liquid but $\mathrm{CT}$ scan with contrast and angiograph showed a giant pseudoaneurysm of ascending aorta with severe local compression of the right lung hilum and right main bronchus and in posterior on the esophagus (Figures 2 and 3).

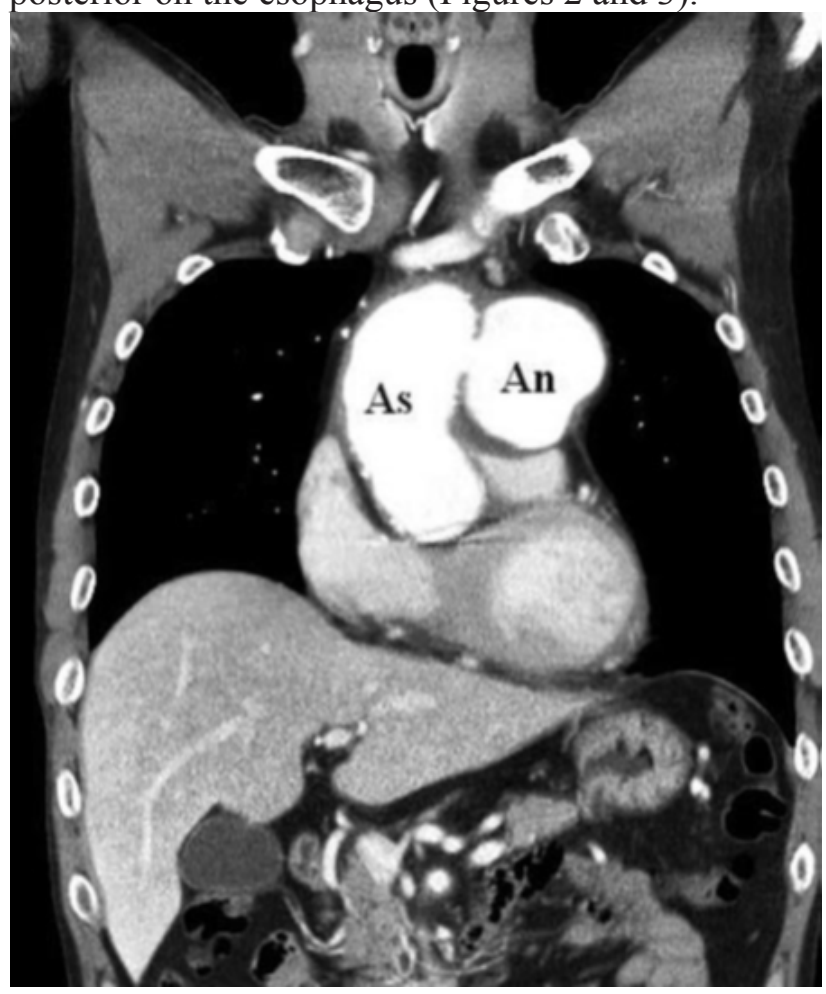

Figure 2

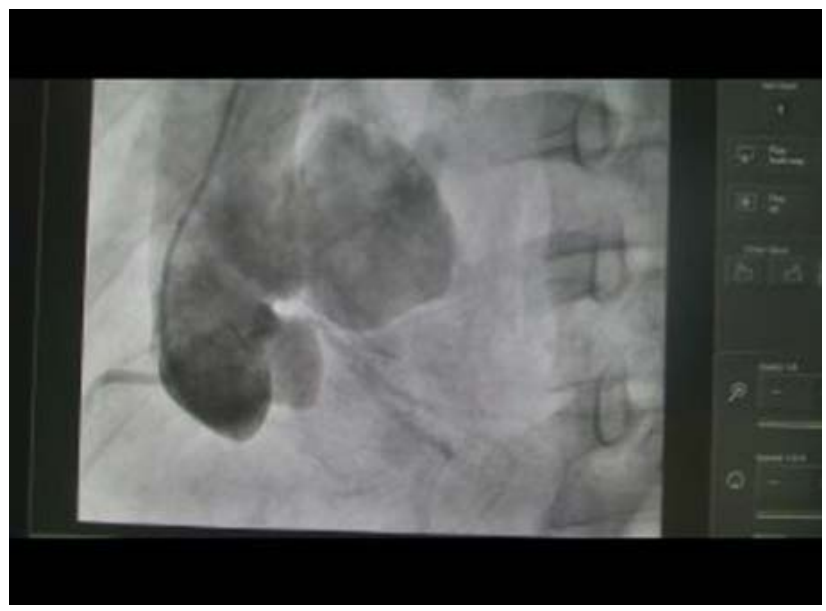

Figure 3

Coronary angiography also shows significant compression and deformation of the left main coronary 
artery without other atherosclerotic lesions (Figure 4) and the angiography reveals the pseudoaneurysm of the ascending aorta without aortic insufficiency.

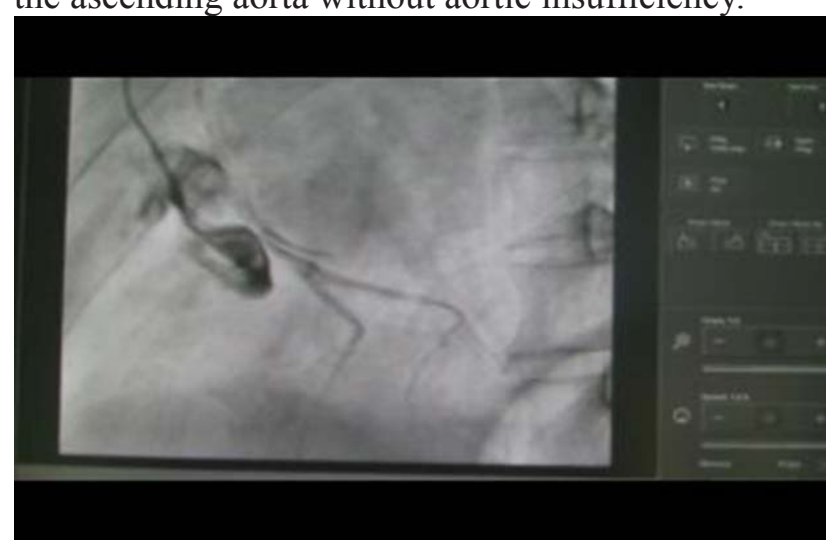

Figura 4

\section{Surgical treatment}

Intraoperatively we found a laceration of $4 / 4$ $\mathrm{cm}$ in posterior wall of ascending aorta $3 \mathrm{~cm}$ above the origin of the left main coronary artery, without connection of the pericardial cavity (Figure 5)

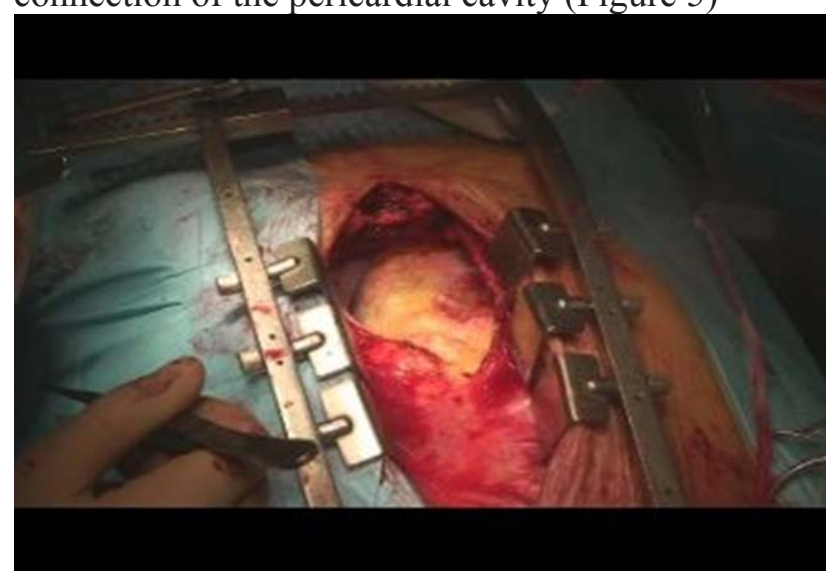

Figure $5 a$

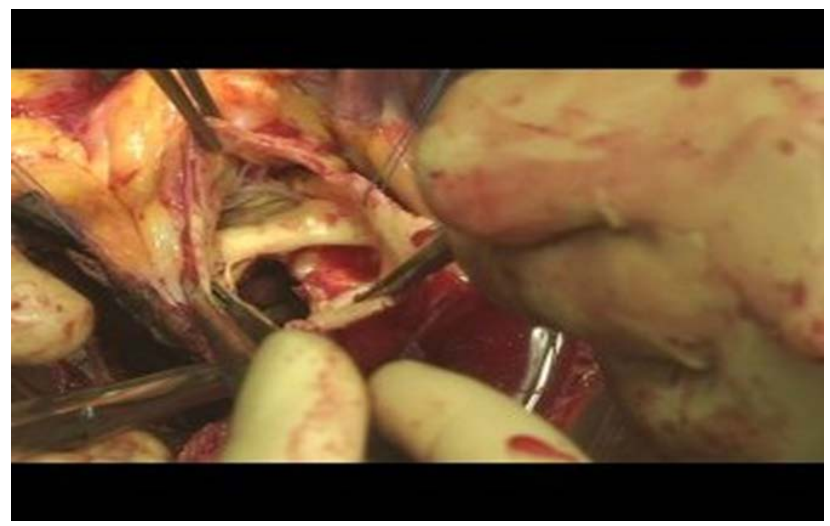

Figure $5 b$

The ascending aorta was replaced with a dacron prosthesis $(25 \mathrm{~mm}$ diameter) in normothermie and total cardiopulmonary bypass (Figure 6 ).

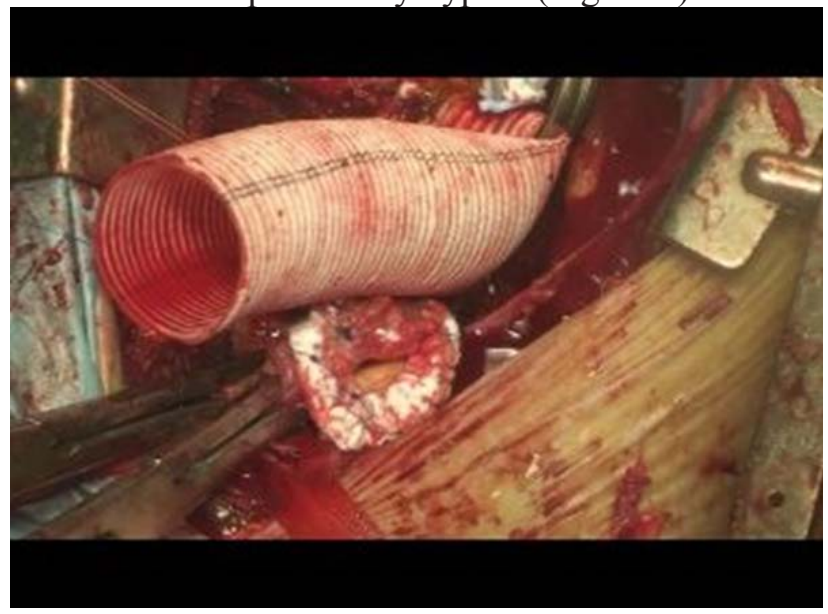

Figure 6

The left ventricle was vented through the right superior pulmonary vein. Due to the difficult approach of the ascending aorta (which was the antero-lateral wall of the pseudoaneurysm ) and due to the high risk of hemorrhage after sternotomy the arterial cannulation was done at the level of the right axillar artery (Figure 7) before sternotomy. After the longitudinal sternotomy the pericardium was opened and the venous cannulation was made directly into the superior and inferior vena cava. In total cardiopulmonary bypass, with the heart in activity, by direct transatrial right approach of the coronary sinus it was administered retrogradely warm blood cardioplegia with rapid cardiac arrest. 


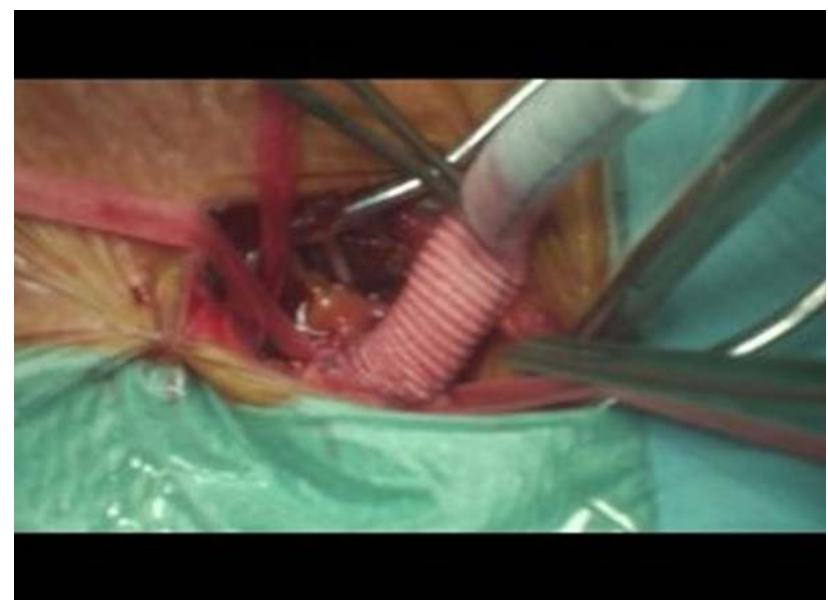

Figure $7 a$

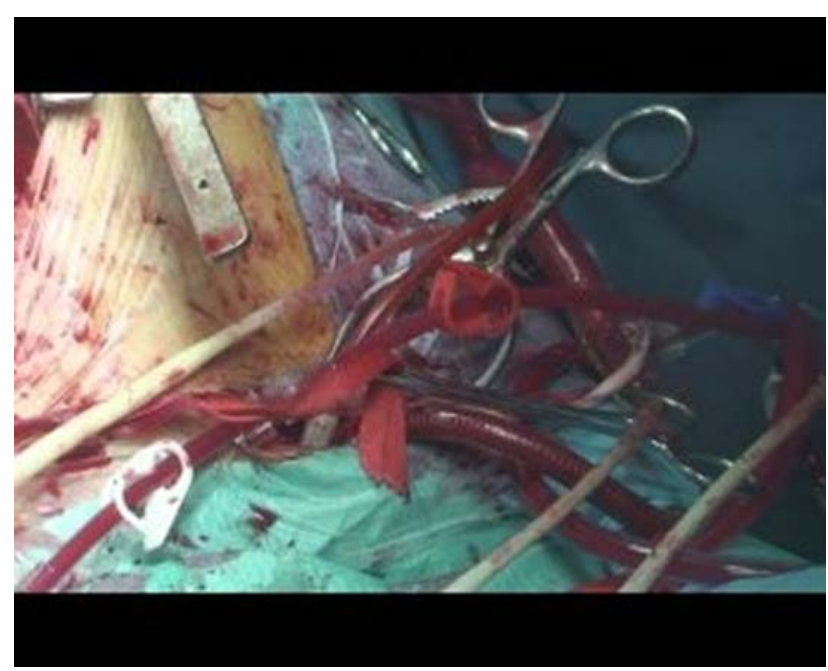

Figure $7 b$

The pseudoaneurysm of the ascending aorta was incised on the left side of the ascending aorta (because the aorta was the right anterolateral wall of the pseudoaneurysm) (Figure 8).

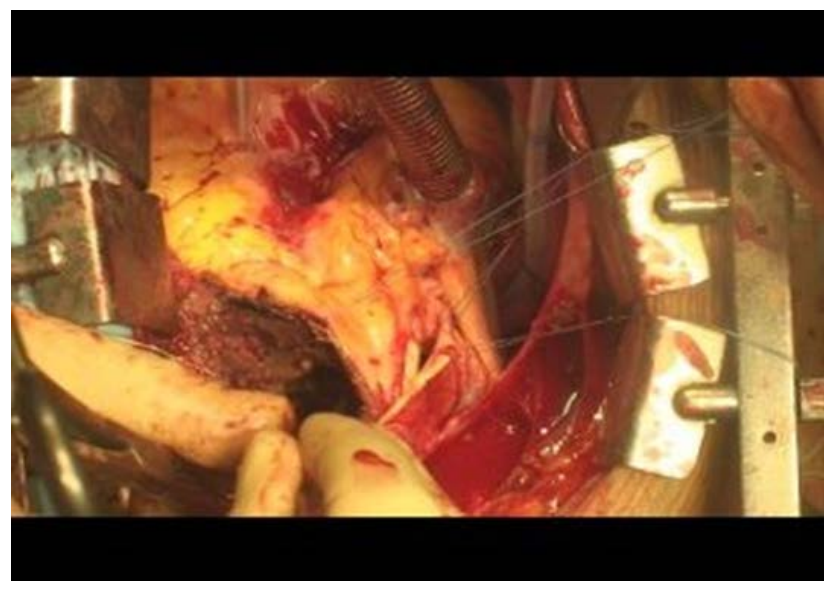

Figure 8

Inside of it there were old thrombi, a laceration of $4 / 4 \mathrm{~cm}$ in posterior wall of ascending aorta $3 \mathrm{~cm}$ above the origin of the left main coronary artery (Figure 9).

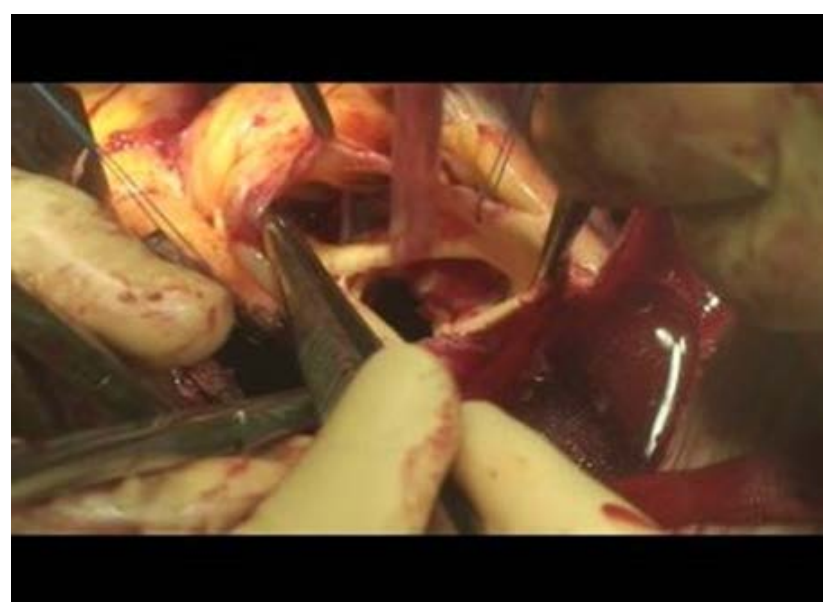

Figure 9

The cross clamping of the ascending aorta was done initially transluminal by a Foley catheter (Figure 10) and after the evacuation of the thrombus and with a metallic instrument (Figure 11). 


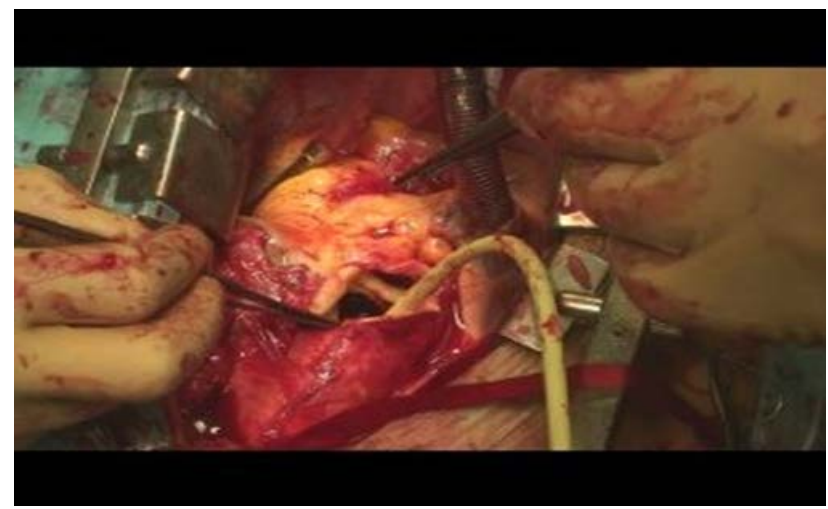

Figure 10

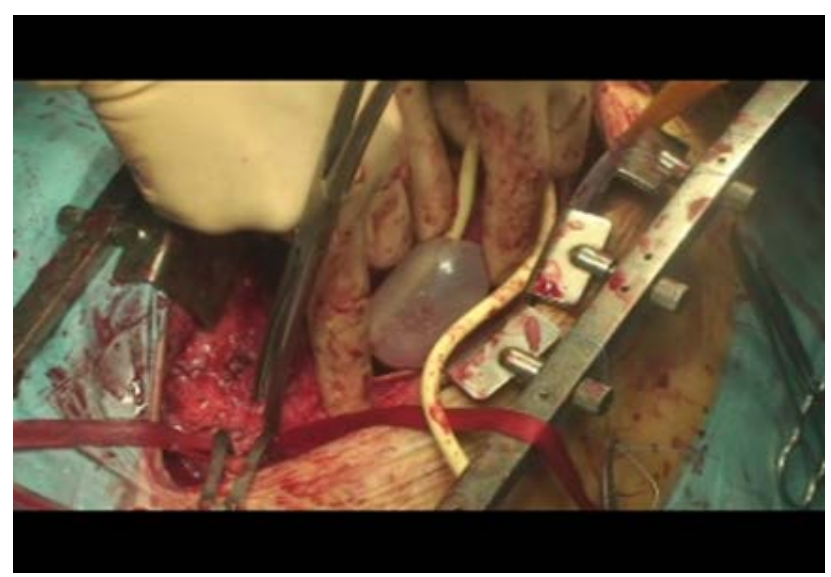

Figure 11

The myocardial protection was done first retrograde because there was no access to the aortic root and afterwards also anterograde directly in to the coronary ostia in an alternative manner. The walls of the pseudoaneurysm after the evacuation of the thrombus: ascending aorta anterior and right, the right pulmonary hilum posterior and right, superior aortic crossa, posterior and to the left pulmonary artery and its bifurcation (Figure 12).

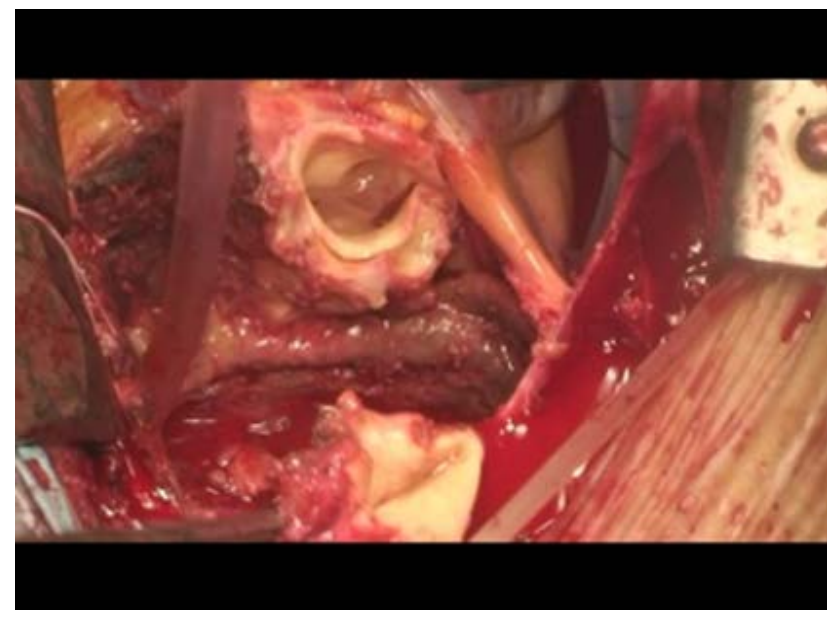

Figure 12

The ascending aorta was excised (Figure 13) and replaced with a impregnated dacron prosthesis $25 \mathrm{~mm}$ diameter (Figure 14). After declamping and reperfusion (Figure 15), the heart was in sinus rhythm with no need of inotropics (Figure 16).

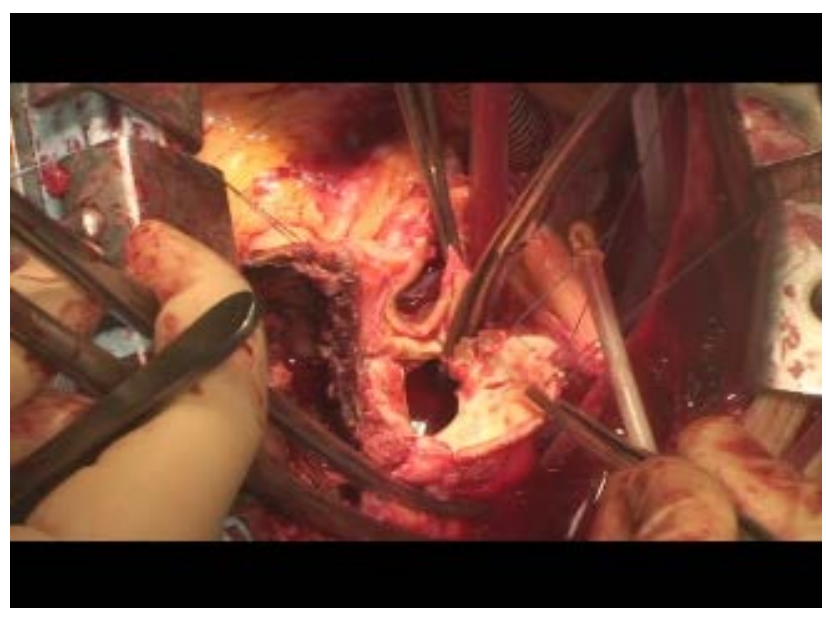

figure 13 


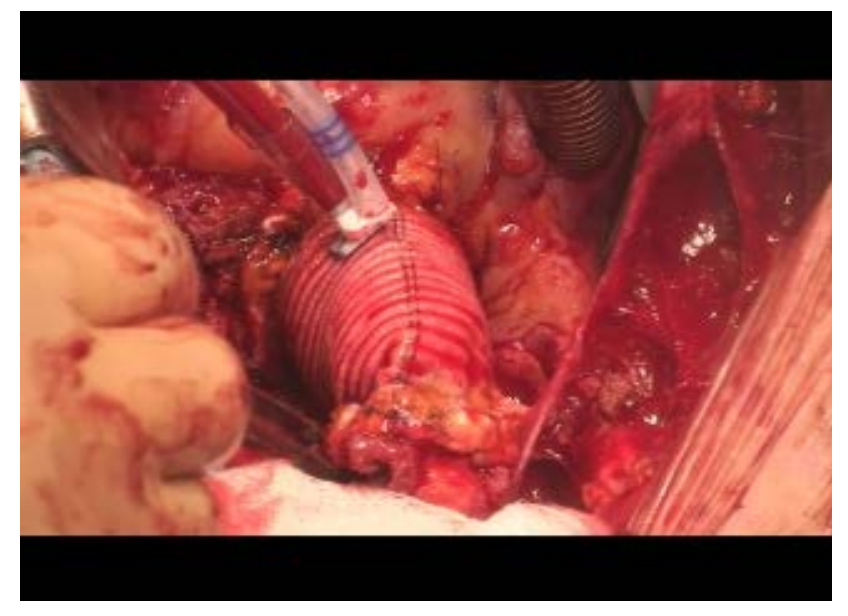

Figure 14

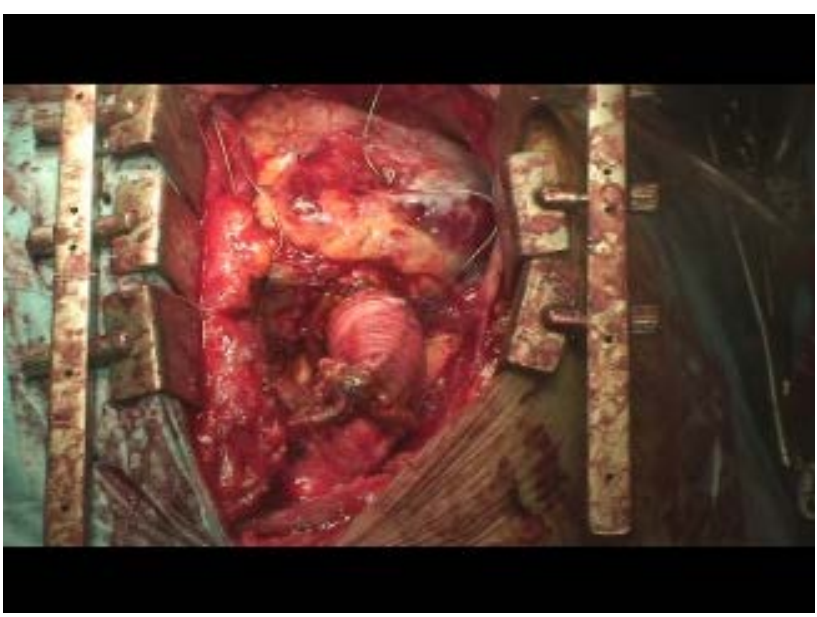

Figure 15

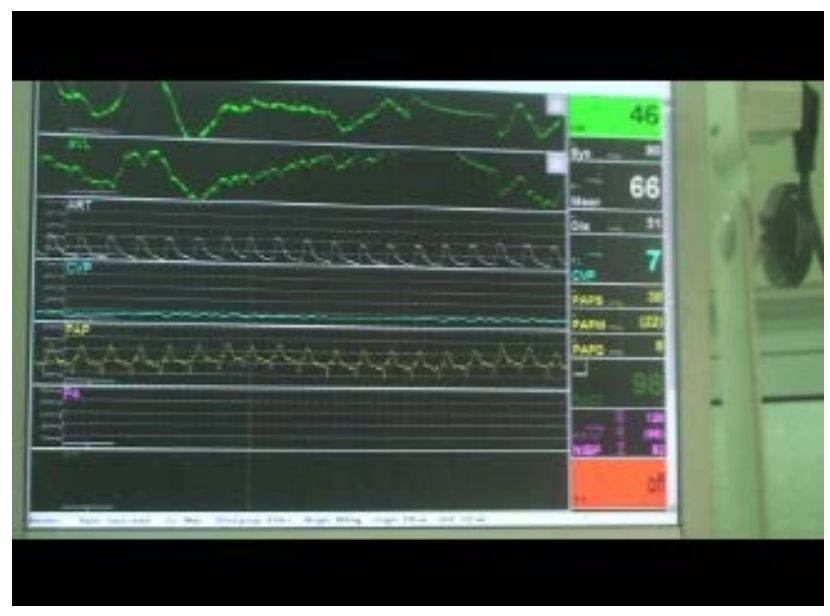

Figure 16

\section{Discussions}

The lactic acid was monitorised in the same time from cardioplegic solution from the coronary sinus - retrograde and from the coronary ostia anterograde (Table I), but without finding significant modifications in between the two type of delivery of the cardioplegic solution (Figure 17).

We can observe a slight increase of the lactic acid due to global myocardial ischemia (Figure 17). Table After declamping due to the „metabolic wash” there

\begin{tabular}{|l|c|c|c|c|c|c|c|}
\hline \multicolumn{1}{|c|}{ Stage } & \multicolumn{3}{|c|}{ Input } & \multicolumn{3}{c|}{ Output } & T test \\
\hline & average & min & max & average & min & max \\
\hline Preclamp & 1.23 & 0.5 & 1.8 & 1.35 & 0.6 & 2 \\
\hline \multirow{2}{*}{$\begin{array}{l}\text { Retrograd } \\
\text { cardioplegia }\end{array}$} & 1.62 & 0.5 & 2.8 & 2.45 & 0.9 & 5.2 \\
\cline { 2 - 8 } & 2.02 & 1 & 3.2 & 2.52 & 1.9 & 4,1 \\
\hline $\begin{array}{l}\text { Anterograd } \\
\text { cardioplegia }\end{array}$ & 1.61 & 1.2 & 2.3 & 4.02 & 2 & 5,1 \\
\hline & 1.63 & 1.3 & 2.1 & 4.46 & 2.4 & 4,5 \\
\hline $\begin{array}{l}\text { Antero and } \\
\text { retrograd } \\
\text { cardioplegia }\end{array}$ & 1.76 & 0.6 & 2.4 & 4.84 & 1.3 & 4 \\
\cline { 2 - 8 } & 1.85 & 1.4 & 2.7 & 5.24 & 3.4 & 5,0 \\
\hline Declamp 0 & 2.07 & 1.2 & 2.5 & 6.97 & 5.6 & 5,4 \\
\hline Declamp 10 & 2.08 & 0.6 & 3.1 & 4.94 & 1.4 & 5,5 \\
\hline
\end{tabular}


is another increase of the lactic acid $w$ the values at 20 minutes (Figure 17).

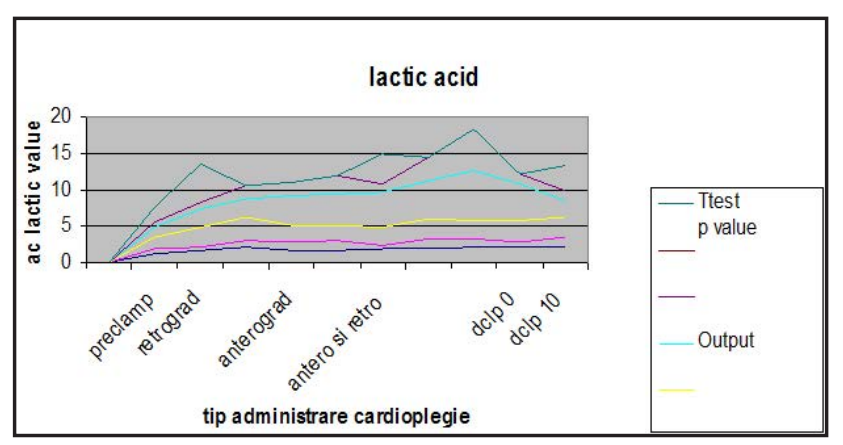

The technical difficulties were the facts that ascending aorta was a wall for the pseudoaneurysm wich determined problems with the arterial cannulation (solved by axillar approach), with the cross clamping of the aorta (solved by endoluminally clamping with Fogarty catheter) and with the administration of the cardioplegic solution (solved by retrograde administration). The postoperative evolution of the patient was good, with 48 hours stay in the intensive care and discharge home 8 days after the operation.

\section{References}

1. Parmley L.F., Mattingly T.W., Manion W.C. \& Jahnke E.J. (1958). Nonpenetrating traumatic injury of the aorta. Circulation. 17, 1086-1101

2. Sabri M.N., Henry D., Wechsler A.S., Di Sciascio G. \& Vetrovec GW. (1991). Late complications involving the ascending aorta after cardiac surgery. Am Heart J. 121, 1779-1783

3. Bozkurt A.K., Besirli K., Yuceyar L. \& Arslan C. (1999). An unusual cause of false aneurysm of the descending aorta due to traumatic disruption of the aorta. Injury. 30, 443-444

4. Quigley M.J. \& Bret P.M. (1995). Occult pseudoaneurysm of the abdominal aorta following gunshot wound: the importance of plain film findings. J Trauma. 38, 269-272
5. Groves L.K. (1964). Traumatic aneurysm of the thoracic aorta. $N$ Engl J Med. 270, 220-224

6. Cabrol C., Pavie A., Gandjbakhch I., Villemot J.P., Guiraudon G. \& Laughlin L. et al. (1981). Complete replacement of the ascending aorta with re-implantation of the coronary arteries, new surgical approach. $J$ Thorac Cardiovasc Surg. 81, 309-315 